\title{
CORPOS QUE PROVOCAM: UMA INVESTIGAÇÃO SOBRE STRIP TEASE MASCULINO
}

\author{
Claudio Nunes ${ }^{*}$
}

\begin{abstract}
RESUMO: Este artigo aborda a prática de strip tease masculino e as possíveis relações com questões da educação. Ao analisarmos uma prática corporal espetacular num contexto particular, podemos perceber a valorização do substrato corporal que se desnuda sensualmente em cena. Assim, os cuidados corporais ocupam grande parte da rotina que antecede estas apresentaçôes. Questôes como gênero, sexualidade e as interfaces com a educação - aqui sinalizadas, ainda que brevemente - serão aprofundadas na continuidade desta pesquisa, interessada também em performances de masculinidades.
\end{abstract}

Palavras-chave: Corpo. Educação. Strip tease.

TEASING BODIES: AN INVESTIGATION ON MALE STRIP TEASE

ABSTRACT: This paper discusses the practice of male strip tease and possible links with education issues. In reviewing a spectacular body practice in a particular context, we can realize the valorization of the substrate body as it sensually undresses on stage. Thus, body care occupies a large part of the routine that precedes these presentations. Issues such as gender, sexuality and interfaces with education - here signaled, albeit briefly - will be detailed in the continuity of this research, also interested in performances of masculinity.

Key words: Body. Education. Strip tease.

Doutorando em Educação na Faculdade de Educação da Universidade Federal do Rio Grande do Sul (UFRGS) e professor de Educação Física. E-mail: claudiorica@hotmail.com 


\section{A pesquisa num contexto específico}

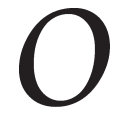

corpo, como substrato central de relações sociais e culturais, parece ocupar espaços em que podemos problematizar tal centralidade. Dessa forma, manifestaçôes espetaculares, como o strip tease $^{1}$ masculino, apresentam elementos radicados em estudos de gênero, sexualidade e performatividade e podem ampliar o debate a partir do campo da educação, uma vez que tais práticas corporais possibilitam questionar hierarquias e conformações de sujeitos. Este texto refere-se à pesquisa iniciada em nível de doutoramento em Educação, que pretende investigar como o corpo masculino que se desnuda, frente a uma plateia majoritariamente homossexual masculina, traz ancorado na fisicalidade questōes acerca de identidade e representação, através de performances encenadas diariamente num local GLS ${ }^{2}$ na cidade de Porto Alegre. Tal espaço caracteriza-se por oferecer uma variedade de serviços e ambientes destinados a adultos, como locadora especializada em filmes eróticos, saunas, lounge bar, cabines e salas de vídeo individuais e coletivas, dark room e glory holes. ${ }^{3}$ No contexto de Porto Alegre, é um lugar diferenciado, pois mulheres frequentam os espaços citados, inclusive desacompanhadas, e a oferta diária de shows de strip tease masculino, no horário de final de tarde, atrai muitos/as interessados/as.

Uma das particularidades atribuídas aos strippers que lá se apresentam e se desnudam coreograficamente é a questão da heterossexualidade, em oposição à homossexualidade dos que assistem a essas performances, já que as mesmas são constituídas pela interação corporal stripperl plateia. Ou seja, é o corpo heterossexual que se despe para corpos no avesso da norma. Este estudo é subsidiado por pesquisa qualitativa de recorte etnográfico, em que foram acompanhadas apresentações diárias de um elenco fixo de strippers masculinos, constituído por 14 sujeitos, ${ }^{4}$ com idades variáveis de 18 a 29 anos. Os registros em diários de campo iniciaram-se em março de 2007 e encerraram-se em agosto de 2009. Nesse período, foram produzidas, além das citadas anotaçōes em diários de campo, entrevistas com dois strippers e com os gerentes do estabelecimento, além de inúmeras conversas informais com todos os sujeitos que se desnudam naquele local, sendo que tais relatos também se constituíram como objeto de análise. O material empírico ainda contou com registros fotográficos de muitos shows e foi parte do trabalho do etnógrafo, 
após "a negociação da sua entrada no campo como observador participante" (Gastaldo, 2005, p. 113).

\section{Corpos espetaculares: o corpo masculino na arena}

A preocupação com o corpo - isto é, os cuidados corporais - parece ser determinante na construção e na apresentação da imagem de homens que fazem strip tease. Não por acaso, todos os integrantes do casting do local pesquisado têm corpos devidamente trabalhados em sessóes de musculação em academias, alguns ainda fazendo-se valer do uso de suplementos alimentares e dietas específicas para a obtenção de uma definição muscular mais apropriada a quem investe nessa prática corporal, visando a uma carreira profissional. Numa das vezes em que os fotografei no camarim, ${ }^{5}$ antecedendo a apresentação, mostraram os suplementos alimentares adequadamente embalados e fracionados em doses diárias a serem tomadas antes e após os exercícios de musculação. Veladamente, há ainda quem faça uso de anabolizantes, buscando aumentar a massa muscular e exibir uma musculatura avantajada, obtida num curto período de tempo, o que proporciona contornos corporais exagerados. Como o consumo desses produtos sem a devida receita médica é uma contravenção, passível de sanções legais, o uso de anabolizantes não é um assunto facilmente abordado com esses sujeitos, pois, em conversas informais, a negativa quanto à utilização era sempre a única resposta.

Assim, percebem-se investimentos e preocupações com a forma física, que resultam em músculos realçados e exibidos na rotina das apresentações, atraindo olhares, interesses, desejos e fantasias de parte dos frequentadores, formado em sua maioria por homens gays, mas não unicamente, já que as apresentações são feitas com a presença de mulheres e travestis na plateia. Os cuidados com uma estética corporal incluem, além de sessões de treinos de musculação, certa disciplina alimentar, com restrições a bebidas alcoólicas e consumo de doces, conforme alguns relatos a mim confiados, indicando condutas prévias à entrada em cena. Esses mesmos cuidados com a aparência e com a estética podem ser reforçados com o uso de lentes de contato azuis, por parte de alguns strippers, como também mais um adorno a ser aplicado no corpo, mais um atrativo do corpo masculino que irá se desnudar frente àquele público. Em uma das entrevistas realizadas, um dos strippers revelou que se 
submetia a sessões de depilação corporal quinzenais numa esteticista, unicamente por causa de suas apresentaçôes. Seus cuidados incluíam também a aplicação de tatuagens pelo corpo, feitas a partir de sua entrada no casting do local; ele relatou ainda o uso de base neutra nas unhas. Justificou tantos investimentos e processos corporais porque tinha que estar "impecável” para os shows. Afora isso, comentou os treinos diários na academia de musculação como forma de aprimorar sua qualidade muscular e manter sua forma física, que lhe rende muitos elogios nas cenas em que se desnuda.

Uma das normas de atuação naquele local orienta quanto à interação entre o corpo do stripper e o corpo do/a espectador/a. Dessa forma, ao atender às condiçôes de trabalho naquele lugar específico, espera-se que o homem que se desnuda, pretensamente heterossexual, interaja corporalmente com os corpos de quem o aplaude - outros homens, mulheres, travestis. Ou seja, enquanto se desnuda, executando coreografias sensuais, rodeado pela assistência, num formato de atuação conhecido como arena, ${ }^{6}$ o stripper oferece seu corpo a outros corpos. A ideia de investimentos na musculatura masculina, originando uma anatomia que será de alguma forma consumida, de acordo com Fraga (2000), através de olhares e mãos alheias, parece traduzir sumariamente as dinâmicas dos shows diários. Perceber os investimentos e os sentidos que os corpos galgam permite olhar esse corpo masculino que se exibe, buscando desnaturalizá-lo, questionando saberes e verdades únicas e incontestes encontradas no campo biológico e investigando a/s maneira/s que o levaram a ocupar naturalmente um lugar destacado na prática encontrada naquele espaço. Para evitar o reducionismo biológico, deve-se perceber o corpo em contextos diferenciados, fruto de processos históricos e culturais, mutáveis, portanto, passível de ser questionado, contradito e plausível de novas interpretaçôes, posto que não encerre uma verdade ou uma resposta única.

Assim, de acordo com "os avanços da Antropologia, cada vez mais está se distanciando o corpo de conceitos e dogmas físico-biológicos de domínio da Medicina e o abrigando em termos de significações e valores culturais" (Benedetti, 2000, p. 10). Pensa-se no corpo como materialidade discursiva, como superfície de contradiçōes e de disputas de significados, um interlocutor de seus próprios discursos, sendo compreendido inclusive por seus rituais, seus modos de vestir-se/apresentar-se/despir-se, com relação aos outros hábitos adquiridos, vivenciados e compartilhados 
nas práticas sociais (Sant'anna, 1993; Del Priori, 1994; Silva, 1999). Assim, se "o corpo é, ele próprio, um processo" (Sant’anna, 1995, p. 12), devemos atentar para as maneiras pelas quais nossos corpos se constroem, são percebidos e valorizados, ou não, ao longo de nossa existência.

A valorização própria do substrato corporal não deixa dúvidas quanto ao oficio de stripper, pois, quando perguntados informalmente se faziam aulas de dança como treinamento para as apresentaçôes, aqueles sujeitos responderam que a técnica da dança era menos importante do que a aparência do corpo. Em conversa com um stripper, o mesmo revelou que, para executar a prática corporal do strip tease, eram necessárias três qualidades corporais, e suas palavras foram: "um semblante bonito, um corpo bonito e um pau grande”. Questionado se não era necessária alguma aptidão específica para a dança, como coordenação motora, ritmo, flexibilidade, alongamento, respondeu que, com as três características citadas, qualquer um, mesmo sem saber dançar, poderia ter sucesso na carreira. Não por acaso, as três qualidades citadas referem-se à materialidade do corpo, pois "é o corpo mesmo, em seu aspecto mais formal e material, quem toma o lugar de adoração fetichista” (Figari, 2007, p. 463).

Aproximações com as questões da educação

É possível contemplar esse corpo masculino que se movimenta sensualmente e se desnuda e analisá-lo a partir de questionamentos que se relacionem a gênero, sexualidades e hierarquias, entre outros marcadores, pois “(...) es a través del cuerpo que el género y la sexualidad se exponen a otros, que se implican en los procesos sociales, que son inscritos por las normas culturales y aprehendidos en sus significados sociales" (Butler, 2006, p. 39).

Podemos pensar, a partir dos estudos pós-estruturalistas, que as observaçôes feitas na arena dos shows diários indicaram que as identidades sexuais (heterossexual, homossexual e bissexual) e as identidades de gênero são constantemente acionadas. As encenações de tirar a roupa sensualmente, coreograficamente, são estabelecidas a partir de diferenças entre as identidades sexuais - stripper homem-heterossexual/ plateia homem-homossexual/mulher heterossexual. De acordo com Silva $(2006$, p. 25): 
As identidades só se definem, entretanto, por meio de um processo de produção da diferença, um processo que é fundamentalmente cultural e social. A diferença, e, portanto, a identidade, não é um produto da natureza: ela é produzida no interior de práticas de significação, em que os significados são contestados, negociados, transformados.

Para o autor, a identidade não pode ser considerada como um produto final, uma coisa; ao contrário, a identidade resulta de um processo, constantemente em construção, e os próprios resultados dessa construção revelam-se indeterminados e imprevisíveis.

Entre os motivos pelos quais a prática do strip tease é analisada pelo seu caráter pedagógico está a produção de identidades e a reafirmação das diferenças entre elas (masculinidades, homossexualidades, heterossexualidades), percebidas naquela arena de atuação. Ao fazer tal afirmação, admito que os processos pedagógicos ali atuam, por estarem relacionados "aos conceitos de identidade e de representação, centrais em qualquer processo educativo, tendo-se presente que os processos educativos são formadores de identidades, e não simplesmente mediadores" (Seffner, 2003, p. 13). Para tanto, considero, de acordo com Silva (2006, p. 46), que a "identidade cultural ou social é o conjunto daquelas características pelas quais os grupos sociais se definem como grupos: aquilo que eles são".

Para Silva (2006), a identidade é sempre construída em relação à diferença, ou seja, aquilo que não se é. Tanto a identidade quanto a diferença são construções operadas a partir do conceito de representação. Para o autor:

A representação é um sistema de significação. Utilizando os termos da linguística estruturalista, isso quer dizer: na representação está envolvida uma relação entre um significado (conceito, ideia) e um significante (uma inscrição, uma marca material: som, letra, imagem, sinais manuais). (2006, p. 35)

A partir do observado na rotina das encenações, dos shows, há uma hierarquia estabelecida a partir da identidade sexual: o homem masculino heterossexual ocupa, inequivocamente, o centro da ação. E, ao assumir o protagonismo das cenas, essa representação de masculinidade reforça-se, empodera-se e, especialmente, distingue-se das demais. Não devemos esquecer que "representação é, como qualquer sistema de significação, uma forma de atribuição de sentido" (Silva, 2000, p. 91). 
E parece-nos que, àquela representação de masculinidade que se insinua, que provoca ao se despir, é atribuído um sentido positivo, valorativo, já que é admirada, cobiçada e saudada com palmas. O próprio cachê destinado a quem se despe traduz um valor conferido à prática corporal desempenhada por aqueles sujeitos. É oportuno, portanto, pensarmos na aproximação entre os conceitos de identidade e de representação.

É na intersecção entre representação e identidade que podemos localizar o caráter ativo de ambas. A representação não é um campo passivo de mero registro ou expressão de significados existentes (...). Os diferentes grupos sociais utilizam a representação para forjar a sua identidade e as identidades dos outros grupos sociais (...). A identidade é, pois, ativamente produzida na e por meio da representação: é precisamente o poder que lhe confere seu caráter ativo, produtivo. (Silva, 2006, p. 47)

Dessa forma, ao apontarmos algumas reflexões sobre conceitos pertinentes ao campo da educação, relacionados à pratica corporal observada, temos o entendimento de que as apresentações cotidianas configuram-se como instâncias pedagógicas, produzindo e reforçando as identidades sociais ali atuantes. Portanto, pedagogias de gênero e de sexualidade são propagadas por intermédio de discursos, coreografias, enunciados, piadas e encenações cotidianas, em que estereótipos são acionados. Tais encenações são criadas a partir de representações de homem heterossexual masculino, valorizadas em detrimento de outras. Ou seja, temos naquela arena, durante as apresentações, uma pedagogia encenada que hierarquiza os homens presentes e, cotidianamente, reforça a heteronormatividade observada nos shows.

\section{Notas}

1. "Strip tease - a form of entertainment, for example in a bar, when a performer removes his or her clothes in a sexually exciting way, usually with music, in front of an audience" Oxford Advanced Learner's Dictionary (7. ed, 2007). Do inglês, o verbo to tease significa provocar, incomodar, perturbar; também indica caçoar de alguém, gozar, brincar. Portanto, o strip teaser é aquele/a que provoca, perturba ao se despir, assim como também pode ser aquele que goza/brinca ao se desnudar.

2. GLS: abreviatura de gays, lésbicas e simpatizantes (Lib \& Vip, 2006).

3. Glory holes são pequenos orifícios feitos nas paredes de madeira na altura dos órgãos sexuais, em que a genitália masculina pode ser introduzida sem que se identifiquem os usuários. Muitas vezes, tais orifícios servem para que sejam introduzidas mãos, que buscam interações com outros corpos. 
Corpos que provocam: uma investigação sobre strip tease masculino

4. Em setembro de 2009, era este o número fixo de strippers masculinos que lá se apresentavam.

5. A sequência destas fotos foi apresentada no $8^{\circ}$ Fazendo Gênero (UFSC), de 25 a 28 de agosto de 2008, no simpósio temático "Gênero e práticas corporais".

6. Arena: tipo de teatro em que a área de representação fica cercada pelo público, com este ocupando toda a volta em torno do palco (Vasconcellos, 1987, p. 20).

\section{Referências}

BENEDETTI, M. Toda feita: o corpo e o gênero das travestis. Rio de Janeiro: Garamond, 2005.

BUTLER, J. Deshacer el género. Barcelona: Paidós, 2006.

DEL PRIORI, M.L. A história do corpo e a nova história: uma autópsia. Revista da USP, São Paulo, v. 13, n. 23, p. 77-98, 1994.

FRAGA, A.B. Anatomias de consumo: investimentos na musculatura masculina. Educação \& Realidade, Porto Alegre, v. 25, n. 2, p. 135-150, 2000 .

FOUCAULT, M. Microfisica do poder. Rio de Janeiro: Graal, 1998.

GASTALDO, É.L. Kickboxers: esportes de combates e identidade masculina. 1995. 185f. Dissertação (mestrado em Antropologia Social) Programa de Pós-Graduação em Antropologia Social da Universidade Federal do Rio Grande do Sul, Porto Alegre.

GASTALDO, É.L. A forja dos homens de ferro: a corporalidade nos esportes de combate. In: FACHEL, O. (Org.). Corpo e significado: ensaios de Antropologia Social. Porto Alegre: Editora da UFRGS, 2001. p. 207-226.

GOELLNER, S. A produção cultural do corpo. In: LOURO, G.; NECKEL, J.; GOELLNER, S. (Org.). Corpo, gênero e sexualidade: um debate contemporâneo na educação. Petrópolis: Vozes, 2003. p. 28-40.

HALL, S. A identidade cultural na pós-modernidade. Rio de Janeiro: DP\&A, 1998.

HALL, S. Quem precisa da identidade? In: SILVA, T.T. (Org.). Identidade e diferença: a perspectiva dos estudos culturais. Petrópolis: Vozes, 2000. p. 103-133. 
LIB, F.; VIP, Â. Aurélia: a dicionária da língua afiada. São Paulo: Editora do Bispo, 2006.

SANT'ANNA, D. Corpo e história. Cadernos de Subjetividade, São Paulo, v. 1, n. 1, p. 113-135, 1993.

SANT'ANNA, D. Políticas do corpo. São Paulo: Estação Liberdade, 1995.

SANT'ANNA, D. Corpos de passagem: ensaios sobre a subjetividade contemporânea. São Paulo: Estação Liberdade, 2001.

SEFFNER, F. Derivas da masculinidade: representação, identidade e diferença no âmbito da masculinidade bissexual. 2003. 260f. Tese (doutorado em Educação) - Programa em Pós-Graduação em Educação da Universidade Federal do Rio Grande do Sul, Porto Alegre.

SILVA, T.T. A produção social da identidade e da diferença. In: SILVA, T.T. (Org.). Identidade e diferença: a perspectiva dos estudos culturais. Petrópolis: Vozes, 2000. p. 22- 40.

SILVA, T.T. (Org.). O que é, afinal, Estudos Culturais? Belo Horizonte: Autêntica, 2006.

VASCONCELLOS, L.P. Dicionário de teatro. Porto Alegre: LPM Editores, 1987.

Recebido em 5 de abril de 2011.

Aprovado em 30 de junho de 2012. 